\title{
Short-Wave Ocean Wave Slope Models for Use in Remote Sensing Data Analysis
}

\author{
Malcolm L. Heron, Senior Member, IEEE, William J. Skirving, and Kelvin J. Michael
}

\begin{abstract}
Recent developments in the directionality of sea waves are reviewed and adapted into a working model for radiometric remote sensing. There is a weight of evidence, both theoretical and observational, that a bimodality exists in the directional wave spectrum for sea surface gravity waves at wavenumbers greater than the value at the peak of the spectrum. We develop a model for the directional splitting which is consistent with observations but which extrapolates in a credible manner to the omnidirectionality observed at wavelengths around $0.3 \mathrm{~m}$. At shorter wavelengths the directional spectrum becomes unimodal and has an approximately constant shape across the gravity-capillary wave regime. A working model is suggested for the directionality of the wave spectrum to improve the analysis of radiometric sea surface data. The model will also be useful for other analyses including active radar techniques which use Bragg scatter.
\end{abstract}

Index Terms-Bimodal wave spectra, directional wave spectra, gravity-capillary waves, wave slopes.

\section{INTRODUCTION}

$\mathbf{R}$ EMOTE sensing of the marine environment has matured considerably over the last decade, and there now exists a wide range of instruments and techniques to measure and monitor the sea surface. Some of the techniques, and in particular radiometry, depend on integrated wave slope distributions rather than spectral amplitudes at specific (Bragg) wavelengths. All wavelengths of the electromagnetic spectrum entering a radiometer from the ocean are reflected or refracted by the sea surface. These effects are dominated by the local angle of incidence of the ray at the sea surface, and the electromagnetic wavelength is a secondary consideration. The angle of incidence is determined by two variables, the zenith angle from the observing instrument to the sea surface, and the slope of the water surface over the scale length of the wavelength, at the point of contact with the water. There is a need for a working model for directionality as well as the mean sea surface slopes in order to interpret data from radiometric remote sensing experiments.

Over the last decade, the changes in sea surface monitoring techniques have been paralleled by changes in our understanding of sea surface directional wave spectra at the high wavenumbers which are relevant to remote sensing with

Manuscript received March 15, 2004; revised October 6, 2004. This work was supported by the Australian Research Council under Grant DP0209275.

M. L. Heron was with the NOAA/NESDIS/ORA, Washington, DC 20910

USA. He is now with the School of Mathematical and Physical Sciences, James

Cook University, Townsville 4811, Australia (e-mail: Mal.heron@ jcu.edu.au).

W. J. Skirving is with the NOAA/NESDIS/ORA, Silver Spring, MD 20910 USA.

K. J. Michael is with the IASOS and ACE Cooperative Research Centre, University of Tasmania, Hobart 7001, Australia.

Digital Object Identifier 10.1109/TGRS.2006.870439 short-wavelength electromagnetic waves. The pioneering work of Cox and Munk [8] produced a simple model with mean-square surface slope (MSS) linear with wind speed in both the along-wind and cross-wind directions, and this has stood the tests of time with many people using the model. In the last decade, however, it has become clear that there is a bimodal feature in the gravity wave directional spectrum at wavenumbers greater than about $1.8 k_{p}$, where $k_{p}$ is the wavenumber at the spectral peak (e.g., [4], [12], [18], [33], [37]). The question arises as to what effect the bimodality might have on directional spectrum models for mean-square wave slope.

There is an associated question which arises from the need for a directional spectral model to use as the basis of data analysis for short-wave remote sensing. The Cox and Munk data give mean-square wave slopes in the along-wind and cross-wind directions and the ratio gives one parameter to describe the directional spreading. This was discussed by Elfouhaily et al., [11], and they adopted a simple ratio of along-wind to cross-wind energy as the spreading parameter. Other spreading models that have been used are the $\cos ^{2 S}(\theta / 2)$ [28], [31], and the $\sec h^{2}(\beta \theta)$ [2], [10] forms, where $S$ and $\beta$, respectively, are the single parameters for the spreading. These models do carry more information than the single parameter and are used to estimate mean-square wave slopes in directions other than parallel and normal to the wind. For example, the Donelan model makes allowance for waves propagating into the wind, and in some applications this is preferable to the Mitsuyasu model.

This paper undertakes a close examination of the Cox and Munk data in the light of recent understanding of the directional wave spectrum and seeks a practical directional spectrum model which can be used with a degree of confidence in the interpretation of remote sensing data. Elfouhaily et al., [11] treated the directional wave spectrum in two sections, guided mainly by the wavenumber dependence, as the long wave section and the short wave section. We are more concerned with the angular spreading, and in the light of recent results on bimodality, we find it convenient to discuss three sections of the ocean wave spectrum.

\section{LONG-WAVE PART OF THE SPECTRUM}

Most of the wave energy is contained in the wavenumber band near to the peak. For coastal and marine engineering, this is the band of most concern, and that is why the early models were validated with wave buoy data near to the peak. This longwave part of the spectrum, however, contributes very little to the mean-square wave slope. This is illustrated in Fig. 1, where we show mean square wave slope for a JONSWAP spectrum over wavelengths down to $4 \mathrm{~m}$ which is about the limit of validity 


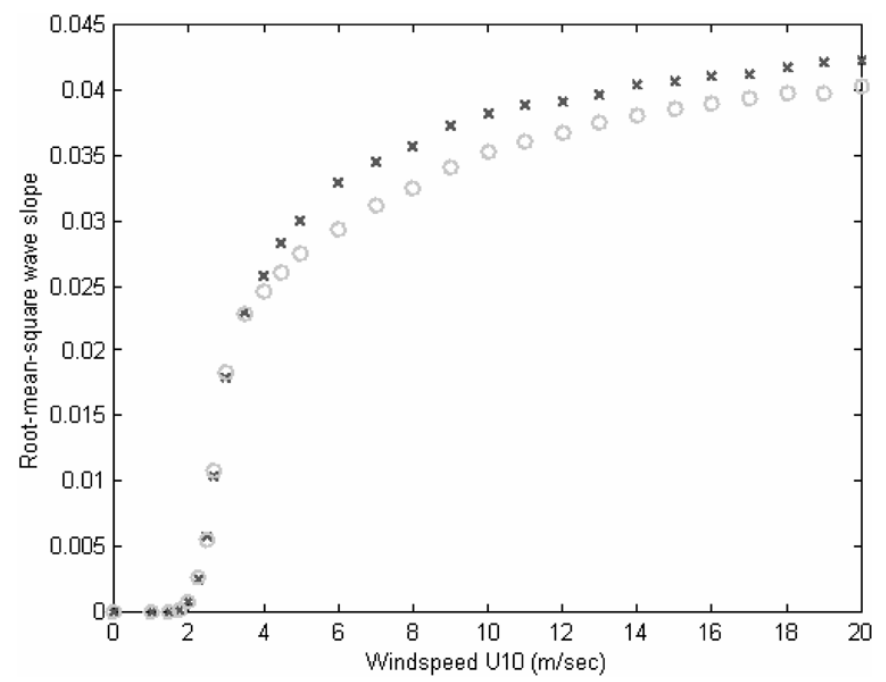

Fig. 1. Root mean square wave slope as a function of wind speed from the JONSWAP model integrating over wavelengths greater than $4 \mathrm{~m}$ for (a) infinite fetch (X) and (b) a fetch of $22 \mathrm{~km}(\mathrm{O})$.

for this model [29]. The mean square wave slopes are generally an order of magnitude less than those for the whole spectrum [8]. Furthermore, Fig. 1 shows the characteristic feature, for both fetches, that the mean square slope is almost independent of wind speed, except at the very low wind speeds.

All of the early models assume a unimodal distribution of wave energy with direction. The $\cos ^{2 S}(\theta / 2)$ [28], [31], and the $\sec h^{2}(\beta \theta)$ [2], [10] forms are explicitly unimodal with the single parameter $S$ and $\beta$, respectively, defining the shape. Elfouhaily et al., [11] used the more general parameter of the ratio, $\Delta=(\phi(0)-\phi(\pi / 2)) /(\phi(0)+\phi(\pi / 2))$, relating the cross-wind energy to the along-wind energy. However, to be useful in remote sensing applications, we require the adoption of an angular shape function, and Elfouhaily et al. settled on the form $\phi(\theta)=(1+\Delta(k) \cos (2 \theta))$. The delta ratio parameter per se is the only one of these parameters which transfers to bimodal spectra, because the ratio is still a measurable parameter. However, it has to be pointed out that any of these models would show broadening if they were fitted to data from a bimodal sea.

In recent years, it has become clear that bimodality in the spreading is a feature of the gravity wave spectrum. This feature was discussed by Banner and Young [4] on the basis of the nonlinear dissipation of wave energy by wave breaking and wave-turbulence interactions of Hasselmann [14]. Young et al., [37] found that the directional spectrum becomes bimodal at $k \approx 4 k_{p}$, and Ewans [12] put the transition between $2 k_{p}$ and $4 k_{p}$, where $k_{p}=\Omega g / U_{10}^{2}$ is the wavenumber at the peak of the wind wave spectrum, where $\Omega=0.84$ for a fully developed sea, and Elfouhaily et al., [11] suggest values for a growing sea.

Ewans' data show an angular separation of the bimodal peaks $\Delta \theta$ commencing at $f / f_{p} \approx 1.4-2.0$ and then reaching a value of about $126^{\circ}$ at $f / f_{p} \approx 4.5$, which is the upper limit of his observed frequency band. Ewans fitted an exponential form

$$
\Delta \theta=\exp \left[5.453-2.750\left(\frac{f_{p}}{f}\right)\right] \quad \text { for } f \geq f_{p}
$$

which gives an asymptotic value of $\Delta \theta=233$ for very large frequencies. For the purpose of extrapolation for $f / f_{p}>4$,

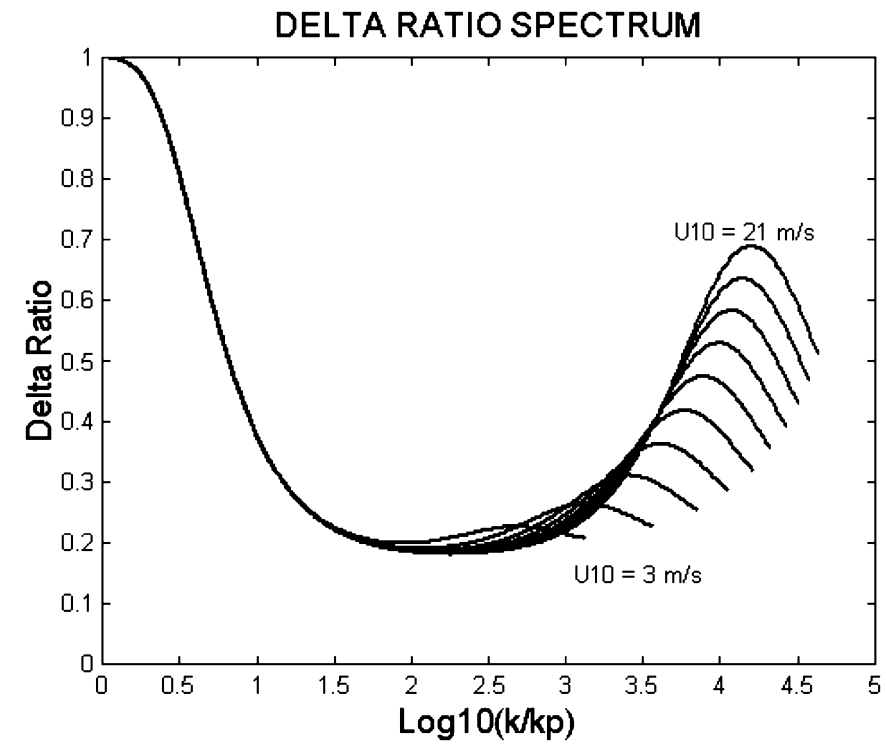

Fig. 2. Elfouhaily et al.'s delta ratio of with-wind to cross-wind elevations for wind speeds from 3 to 21 in steps of $2 \mathrm{~m} / \mathrm{s}$. The abscissa is normalized wavenumber and shows the control of normalized wavenumber at the gravity wave peak. The gravity-capillary peak is at constant wavenumber, $k=370 \mathrm{rad} / \mathrm{m}$

we would caution the use of this expression and observe that Ewans' $\Delta \theta$ values for $3.5<f / f_{p}<4.5$ appear to have already reached a maximum of about $126^{\circ}$. The results of Hwang et al. [18] also show $\Delta \theta$ reaching a maximum at around $k / k_{p} \approx 8$.

Elfouhaily et al., [11] adopted the delta ratio as the spreading parameter, which is still of interest in a bimodal distribution because it is an observable parameter. Their delta ratio is plotted in Fig. 2 using normalized wavenumber on the abscissa. This model captures the spreading - which we now know is due largely to bimodality - for $k / k_{p}>1$ and approaches a constant level at about $k / k_{p} \approx 20$. This is generally consistent with Ewans' data at the low-frequency end of the data set, but for higher wave numbers, we need to have a model which includes bimodality and which takes account of the fact that the peak separation approaches a constant level at high wavenumbers. It is with some trepidation that we divert from Ewans' best fit form, but we are seeking the best representation of the observations at high $f / f_{p}$ values. This may be a better basis for extrapolation for $f / f_{p}>4.5$ and is consistent with Elfouhaily et al. [11] and the previous work that they took into account in their synthesis. Using Ewans' style of model we suggest that the exponential expression for $\Delta \theta$ needs to be constrained to an asymptotic value of $126^{\circ}$. The model needs to accommodate the observation that the bimodality commences at $k / k_{p} \approx 2-4$, and the shape is fitted to the data of Hwang et al., [18] by using the cube of the normalized frequency to bring $\Delta \theta$ to its asymptotic value more quickly. The three fitted parameters are included in the suggested form

$$
\Delta \theta=\exp \left[4.836-7.408\left(\frac{k_{p}}{k}\right)^{\frac{3}{2}}\right]
$$

and is shown in Fig. 3(a) as a frequency-dependent function along with Ewans' model. In Fig. 3(b), we show the bimodal peak separation as a wine glass-shaped function of normalized wavenumber. The data points are from Hwang et al., [18] we 


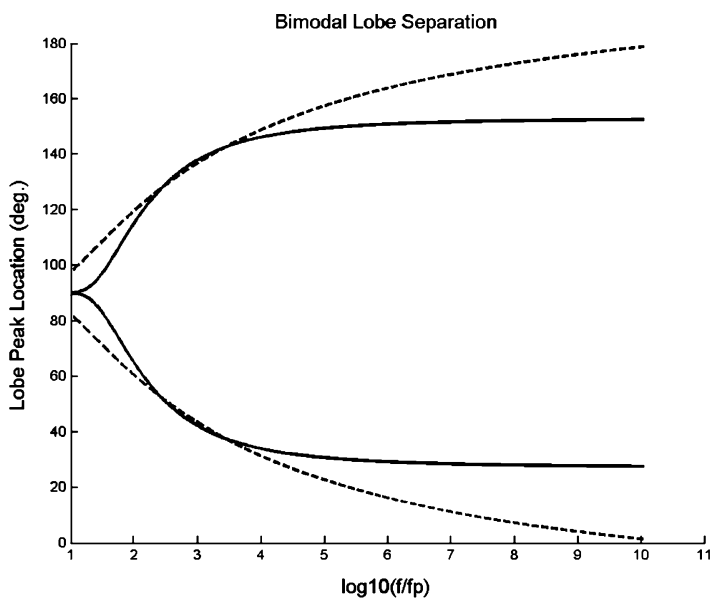

(a)

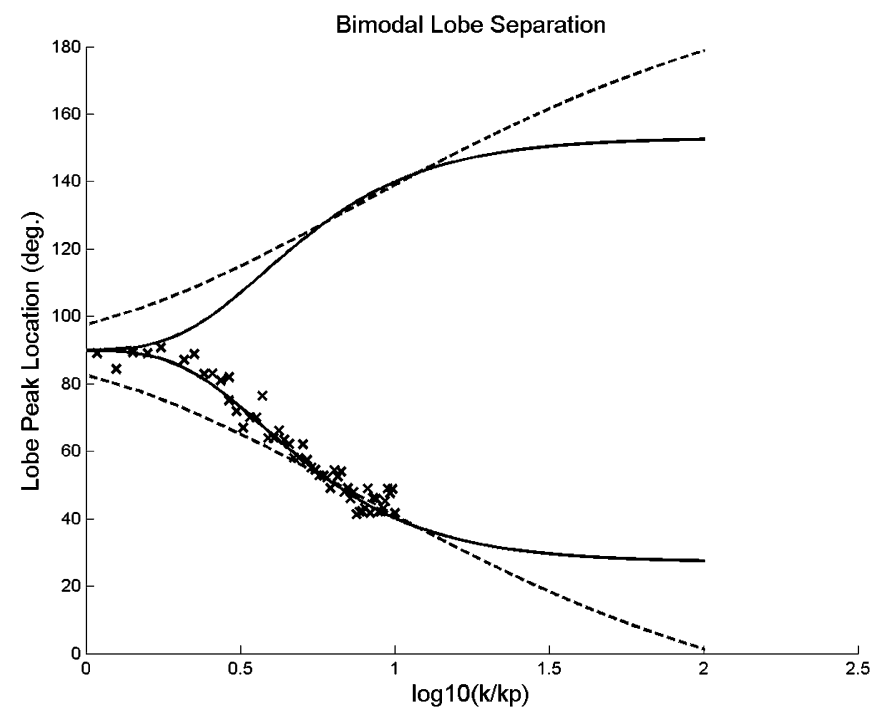

(b)

Fig. 3. New model (solid line) for the separation of lobe peaks in the bimodal directional spectrum compared with Ewans' model (dashed line) (a) As a function of normalized frequency. (b) With normalized wavenumber. The data points (x) are scaled from Hwang et al., [18, Fig. 10(a)].

chose not to use their fitted form because their best fit was a second-order polynomial which is not optimal at the high wavenumber end of the data set and, unlike the exponential, does not extrapolate to an asymptote.

Also of interest is the delta ratio parameter for spreading of the spectrum, and this is shown in Fig. 4, where the new model (solid line) is compared with that from Ewans' model (dashed line). Our immediate interest is to examine the way bimodality manifests itself in the high wavenumber part of the saturation spectrum.

\section{INTERMEDIATE PART OF THE SPECTRUM}

There is a dearth of experimental observations between the upper limit of wave buoys $\left(k / k_{p} \approx 20\right.$ in Ewans' data) and the lower limit of microwave results at wavelengths of about 0.3 m. High-frequency radar results (e.g., [15]) have shown that the spreading is greater than that given by the JONSWAP model. There is evidence that the spectrum is very broad, almost

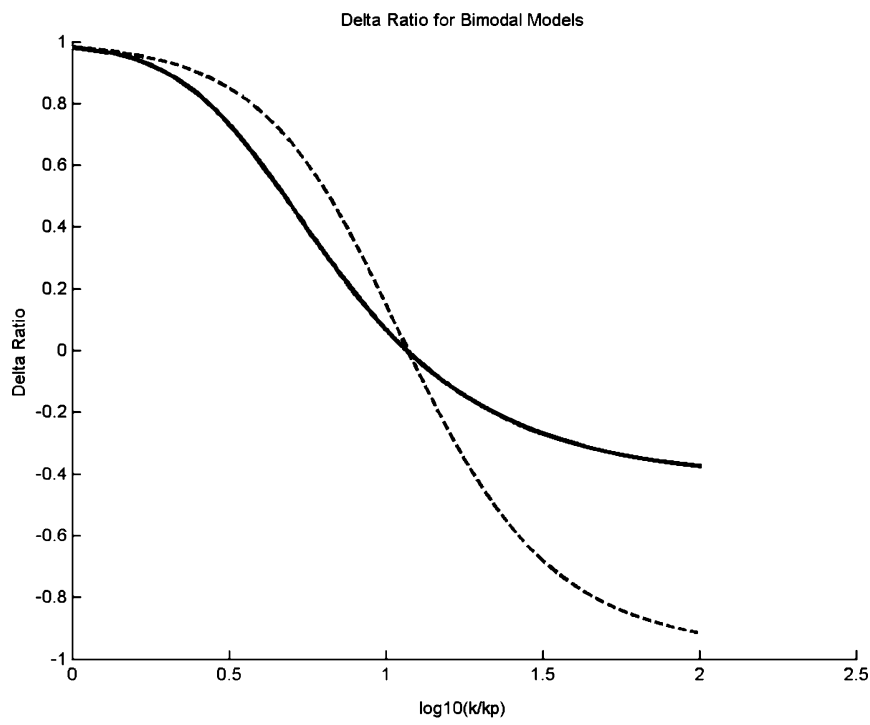

Fig. 4. Spreading parameter $\Delta(k)$ for the new bimodal spreading model (solid line) and that for Ewans' model (dashed line). $\Delta(k)$ is negative when the cross-wind spectral magnitude exceeds the along-wind value.

omnidirectional, at wavelengths around $0.3 \mathrm{~m}$. Keller and Plant [22] observed scatter cross sections from the sea surface during the Tower Ocean Wave and Radar Dependence Experiment and found that at L-band (Bragg wavelengths about $0.28 \mathrm{~m}$ ), the cross sections were nearly isotropic with no dependence on wind speed except at very low wind speeds. This contrasted with the $\mathrm{Ku}$-band cross sections (Bragg wavelengths about $0.03 \mathrm{~m}$ ) which showed wind dependence and increased energy in the along-wind direction. These authors remark that cross sections at most microwave frequencies (X-band and above) are like their $\mathrm{Ku}$-band observations, and that the L-band result represents a quite abrupt change in the scattering process.

Banner [2] reported a continued increase in spreading from a theoretical model beyond $k / k_{p} \approx 2.56$, with a spreading cutoff at much shorter scales consistent with photogrammetric data presented by Banner et al. [3]. These photogrammetric data showed nearly omnidirectional spectra at wavelengths of $0.3 \mathrm{~m}$.

A classic illustration of a transition between the long-wave spectrum and the short-wave spectrum comes from the data of Cox and Munk [8]. Fig. 5 shows their data for mean square slope as a function of wind speed, replotted as suggested by Hwang and Wang [19], to separate the two cases of slick and no-slick. The artificial slick has nulled the waves with wavelengths smaller than about $30 \mathrm{~cm}$, so the crosses represent the mean square slope integrated over all wavelengths greater than about $0.30 \mathrm{~m}$. This mean square wave slope integral is almost independent of wind speed as long as the wind speed is greater than about $3 \mathrm{~m} \mathrm{~s}^{-1}$. The value of mean square slope is low, below $0.02 \mathrm{~m}^{2}$ and consistent with the integral for the JONSWAP spectrum as shown in Fig. 1 for wavelengths greater than $4 \mathrm{~m}$. In contrast, the circles are for no-slick conditions with all wavelengths contributing, and the mean square wave slope is linear with wind speed. Two important results come from these considerations. One is that it is the short waves which dominate in the mean square wave slope phenomena, and the other is that there is a clear demarcation between the processes of short waves and long waves at some transition wavelength near $0.3 \mathrm{~m}$. 


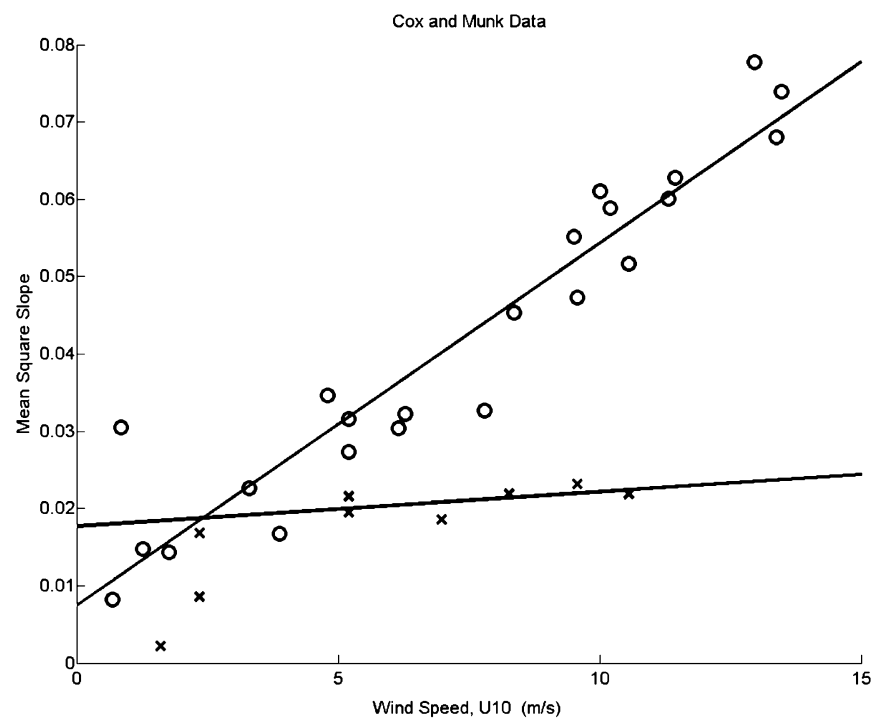

Fig. 5. Magnitudes of mean-square-slope from Cox and Munk's data for clean sea $(\mathrm{o})$ and oil-slick sea $(\mathrm{x})$ with derived wind speeds at 10-m altitude. The best straight line for clean sea is fitted to all the points, while for the oil-slick sea we used points at $\mathrm{U} 10>3 \mathrm{~m} \mathrm{~s}^{-1}$ (after [19]).

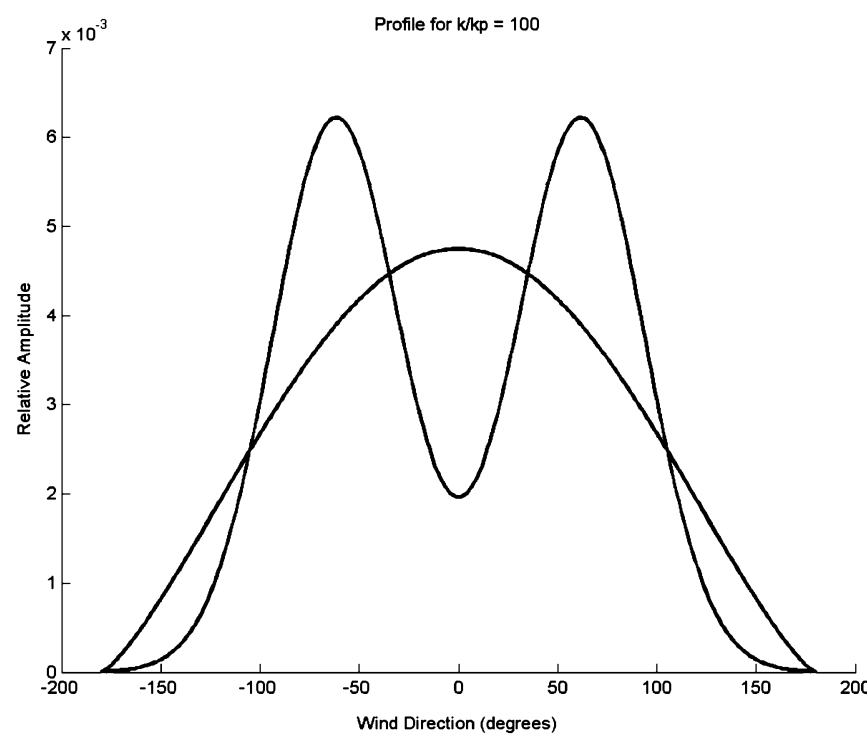

Fig. 6. Bimodal shape for the model spreading function as it approaches its asymptotic form at large $k / k_{p}$ values. The unimodal shape is the best-fitting $\cos ^{2 S}(\theta / 2)$ form, which is the representation previous models would use. $(S=$ $0.65)$.

The reports of omnidirectional spectra at wavelengths in the $0.3-1.0 \mathrm{~m}$ wavelength band are not inconsistent with the bimodal spectrum at longer wavelengths. Fig. 4 showed that the model for a bimodal spectrum has the delta ratio for along-wind to cross-wind directions at about -0.3 at $k / k_{p} \approx 100$, and the lobe shape is shown in Fig. 6. The best-fitting $\cos ^{2 S}(\theta / 2)$ unimodal shape is also shown in Fig. 6, with $S=0.65$ and delta ratio of +0.22 which is consistent with values for the model of Elfouhaily et al., [11]. There appears to be a fairly abrupt change in the spectrum somewhere above $k \approx 21 \mathrm{rad} / \mathrm{m}$, where the bimodal spectrum of gravity waves is overtaken by a gravity-capillary wave regime with different characteristics.

In the model of Elfouhaily et al. [11], there is a natural transition point between the long-wave and the short-wave parts of

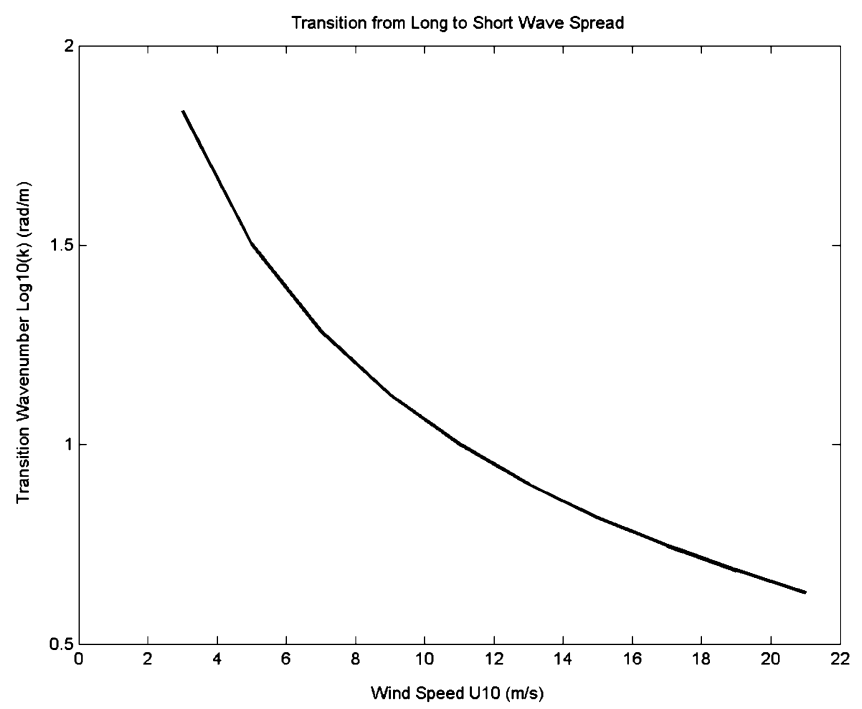

(a)

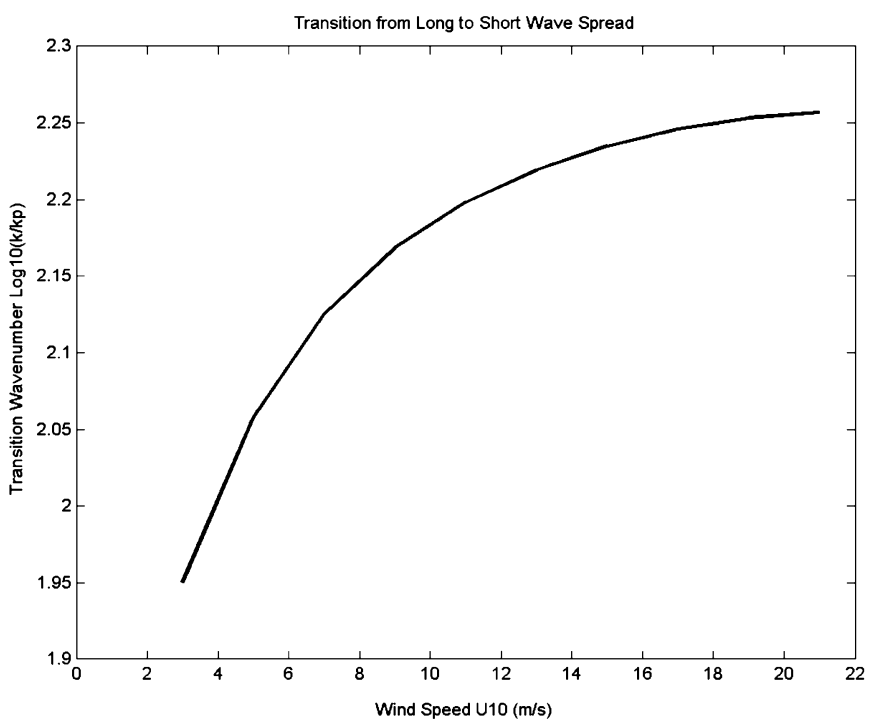

(b)

Fig. 7. Transition point between long waves (gravity waves) and short waves (gravity-capillary waves) is also the transition between bimodel and unimodel spreading. (a) Transition given by Elfouhaily et al. [11] in terms of wavenumber, $k$. (b) Transition is more precisely specified by normalized wavenumber. [Note the expanded scale in (b).]

the spectrum in the expression for spreading when the contributions are equal from the equilibrium gravity wave processes and the gravity-capillary wave regime. This transition point is defined when the contributions from each term are equal

$$
a_{p}\left(\frac{c}{c_{p}}\right)^{2.5}=a_{m}\left(\frac{c_{m}}{c}\right)^{2.5}
$$

where $c$ is the wave celerity, $c_{p}$ is the wave celerity at the gravity wave peak, $c_{m}$ is the celerity at the gravity-capillary wave peak, $a_{p}$ is a constant, and $a_{m}=0.13 u_{*} / c_{m}$.

Fig. 7 shows how the transition wavenumber varies with wind speed in the Elfouhaily et al. model. The lower panel shows that the variability is reduced when the transition wavenumber is scaled by the wavenumber of the gravity wave peak, with 


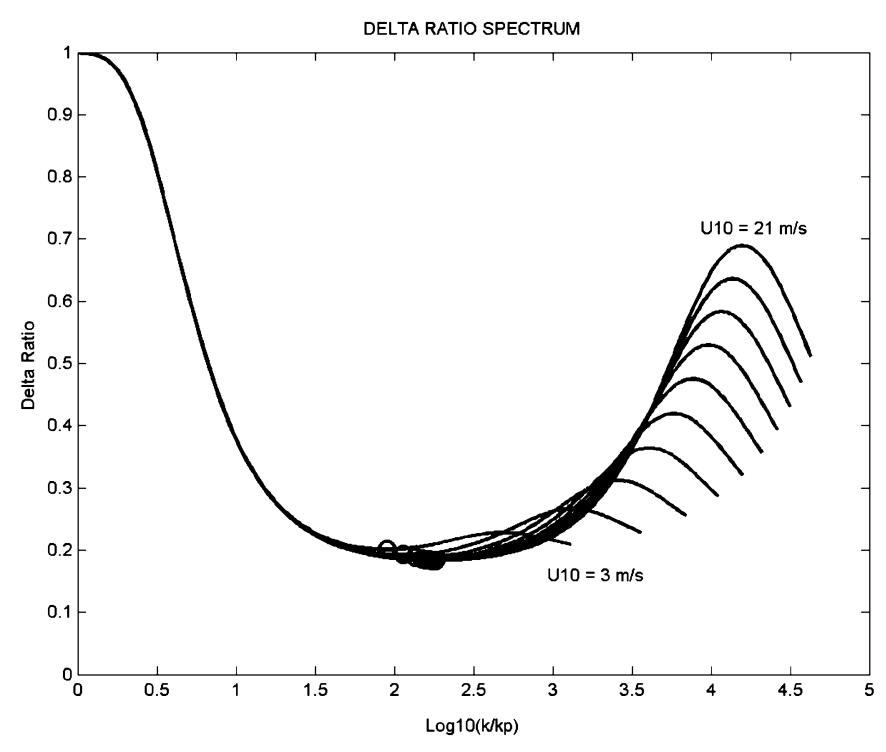

Fig. 8. Spreading parameter delta ratio from the model of Elfouhaily et al. [11] plotted with the normalized wavenumber to remove wind dependence in the long wave (gravity wave) part of the spectrum. The circles mark the transition between the long wave and the gravity-capillary wave parts of the spectrum.

an asymptotic approach to 178 at high wind speeds. Thus, the normalized transition wavenumber, $k_{t} / k_{p}$, is in the range

$$
89>\frac{k_{t}}{k_{p}}>178
$$

for windspeeds above $3 \mathrm{~m} \mathrm{~s}^{-1}$. Fig. 8 shows the delta ratio spreading parameter with normalized wavenumber, with the transition wavenumber, $k_{t}$, marked for each windspeed. The $k_{t}$ values are sufficiently well bunched that we could take a single $k_{t} / k_{p}$ value for the transition wavenumber in a model.

This transition is also shown in the data of Jahne and Riemer [20] taken in the large Delft wind wave facility with optical sampling. The three-dimensional spectra shown in their paper for different wind speeds often show the bimodal spectral shape merging into a unimodal distribution at short wavelengths. A steady progression can be seen with the bimodal peaks decaying and the central unimodal peak dominating as the wavenumber increases. We scaled the ratio of degree of saturation at $30^{\circ}, 60^{\circ}$, and $90^{\circ}$ to that at $0^{\circ}$ for each wind speed, and these are shown in Fig. 9. At higher wind speeds, the effect is clearer where a near omnidirectional spread (with ratios nearly equal to, and usually greater than 1) at lower wavenumbers changes to a separation of the ratios, representing a central lobe. The transition wavenumbers range from about $k=40 \mathrm{rad} / \mathrm{m}$ at $\mathrm{U} 10=17.2 \mathrm{~m} \mathrm{~s}^{-1}$ to about $k=60 \mathrm{rad} / \mathrm{m}$ at $\mathrm{U} 10=7.3 \mathrm{~m} \mathrm{~s}^{-1}$. We extended this analysis by fitting $S$-values to each of Jahne and Riemer's curves. These are shown in Fig. 10, plotted on a normalized $\log _{10}\left(\mathrm{k} / \mathrm{k}_{\mathrm{p}}\right)$ abscissa. The transition wavenumbers are summarized in Table I and compared with those derived from the Elfouhaily transition. The transition wavenumbers in the middle of the transition zone are greater from the Jahne and Reimer [20] data, but still lie in the flat region of the curves shown in Fig. 8. To be consistent with these data, our model will take the Elfouhaily et al. transition wavenumbers to designate the beginning of the transition which occurs at $\log _{10}\left(\mathrm{k} / \mathrm{k}_{\mathrm{p}}\right)=2.18$ for the Jahne and Riemer data. It is clear from Fig. 10 that the transition zone is
TABLE I

TRANSITION WAVENUMBER, WIND SPEED, NORMALIZED TRANSITION WAVENUMBER; USING DATA FROM JAHNE AND RIEMER, [20] (J \& R), AND ELFOUHAILY et al. [11] (ELF)

\begin{tabular}{|l|l|c|c|c|}
\hline $\mathrm{U} 10(\mathrm{~m} / \mathrm{s})$ & $k_{p} \mathrm{rad} / \mathrm{m}$ & $k(\mathrm{~J} \& \mathrm{R})$ & $\log 10\left(k_{t} / k_{p}\right)(\mathrm{J} \& \mathrm{R})$ & $\log 10\left(k_{t} / k_{p}\right)(\mathrm{Elf})$ \\
\hline 7.3 & 0.137 & 57.5 & 2.62 & 2.1 \\
\hline 8.9 & 0.101 & 63.1 & 2.65 & 2.1 \\
\hline 12.2 & 0.0471 & 47.9 & 2.80 & 2.3 \\
\hline 17.2 & 0.0289 & 39.8 & 2.96 & 2.3 \\
\hline
\end{tabular}

controlled by the wind wave spectrum because the $\mathrm{k} / \mathrm{k}_{\mathrm{p}}$ normalization works so well. Note that the wind wave control continues across the transition zone and influences the first part of the capillary wave band.

\section{Short-WaVe Part of THE SPECTRUm}

Wave slope studies for short-wavelength waves can be grouped into five categories according to the techniques used. The earliest systems involved the measurement of sun glint using photographs (e.g., [8] and [32]). Since then, systems based on reflected light beams (e.g., [35]), refracted light beams (e.g., [7], [13], and [26]) fast-response-elevation probes (e.g., [30]), and radar (e.g., [6], [21], [34], and [38]) have been applied to the measurement of short-wave statistics.

Although there have been many studies published on the relationship between wind speed and wave slopes, it is not straightforward to make direct comparisons of the results. Fig. 11 shows selected experimental results from studies representing the various techniques used to measure wave slopes. To enable a comparison, the wind speeds have been normalized to a 10-m level.

In Fig. 11, the points for Cox and Munk [8] (open ocean measurements) and those from the JONSWAP model, have been plotted with different symbols from the remainder of the studies, which are based on tank experiments. Also, note that Cox [7] collected three sets of data with different fetches, as did Long and Huang [26].

From Fig. 11, it can be seen that there is a self-consistency among the results derived in wind-wave tanks. This relationship between MSS and wind speed is roughly linear with a larger slope than the relationship exhibited by the Cox and Munk data, which is itself considerably steeper than relationship from the JONSWAP model. The JONSWAP data do not include the effect of the steeper short wavelength waves, and therefore underestimate the actual slope distribution of the open ocean. The tank data do not include long wavelength waves. The open ocean observations of Cox and Munk include the contribution of both long wavelength gravity waves and short wavelength waves to the slope distribution.

The tank experiments exhibit slopes significantly larger than those recorded by Cox and Munk, and this difference is likely to be a combination of factors. First, the waves in a wind-wave tank do not all move along the axis of the flume. A significant percentage of them move in other directions, some even at right angles to the direction of the wind [9], [25], [29]. The waves, which do not move along the axis of the flume, eventually hit the side walls and reflect. This has been modeled by Heron and Bold [16] and shows that there is increased wave amplitude at the sides of the tank, and a small enhancement in the middle. If the 

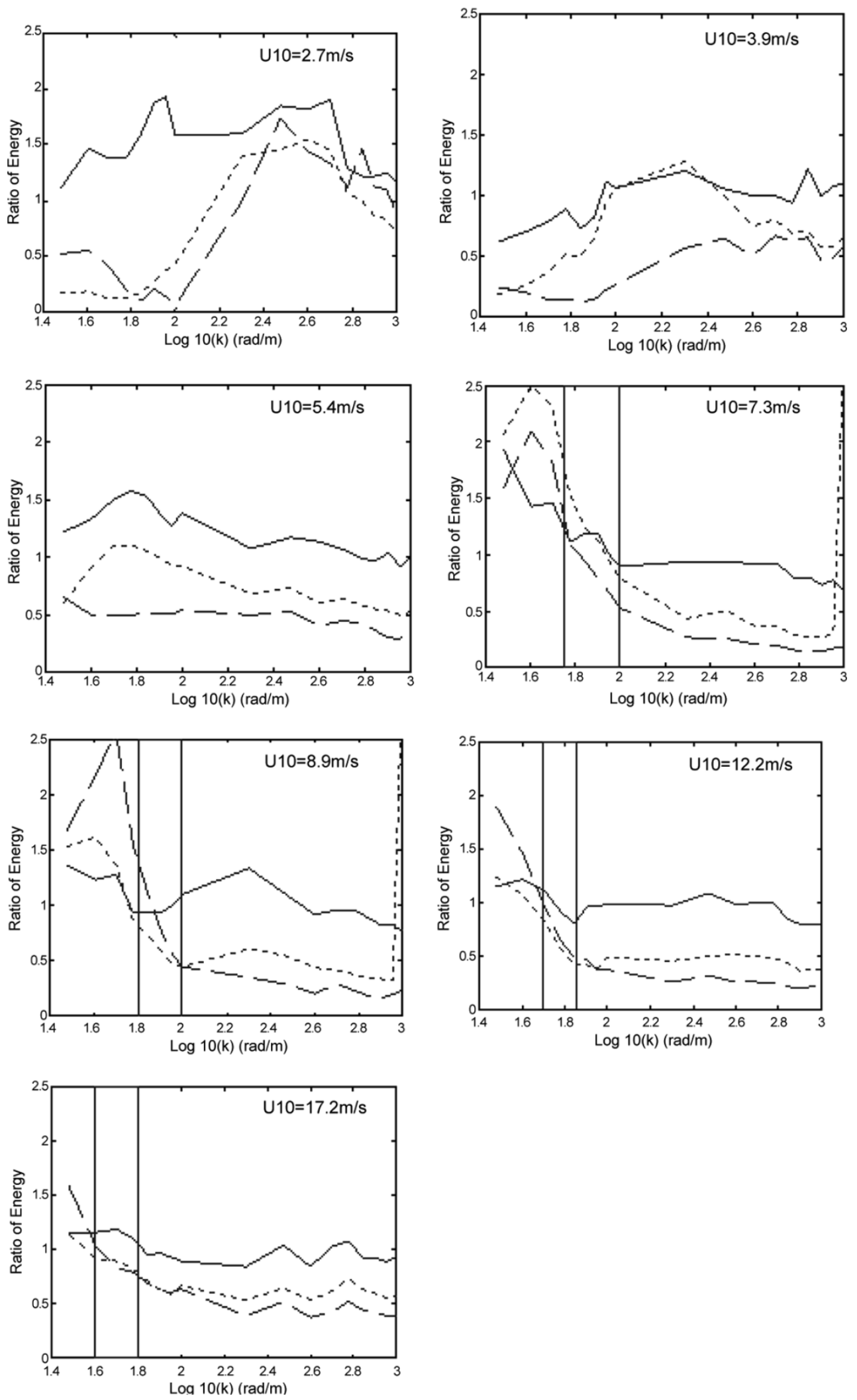

Fig. 9. Jahne and Riemer [20] data replotted to show the ratio of spectral energy at angles $30^{\circ}$ (solid), $60^{\circ}$ (dotted), and $90^{\circ}$ (dashed), normalized to the $0^{\circ}$ value for windspeeds 2.7 to $17.2 \mathrm{~m} \mathrm{~s}^{-1}$ as marked. The vertical bars designate regions of change discussed in the text.

reflections off parallel side walls are perfectly lossless, and the wind is directed along the axis of the flume, then the directional spreading of the wave spectrum is not changed by the reflection process. Second, the wind waves in tank experiments are usually steeper than equilibrium waves by virtue of their early stage of development.

In addition to this effect, the tank experiments present a water surface with a more uniform distribution of short wavelength 


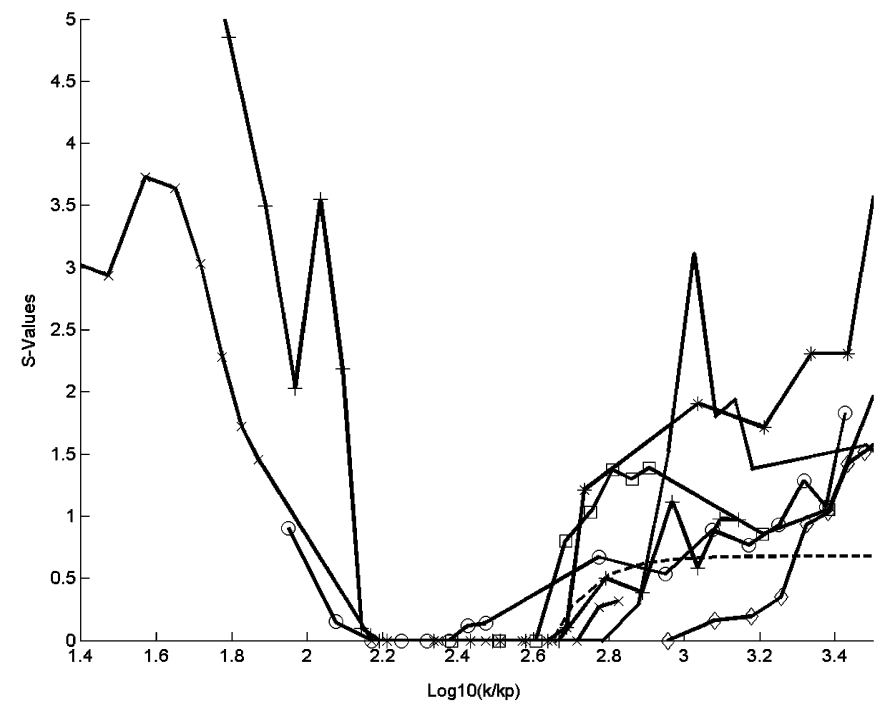

Fig. 10. Spectral spreading parameter $S$ derived from the data of Jahne and Riemer [20] for wind speeds $2.7 \mathrm{~m} / \mathrm{s}(\mathrm{x}), 3.9 \mathrm{~m} / \mathrm{s}(+), 5.4 \mathrm{~m} / \mathrm{s}(\mathrm{o}), 7.3 \mathrm{~m} / \mathrm{s}\left(^{*}\right)$, $8.9 \mathrm{~m} / \mathrm{s}(\square), 12.2 \mathrm{~m} / \mathrm{s}(\bullet)$, and $17.2 \mathrm{~m} / \mathrm{s}(\diamond)$. The dashed line is the model form for $\log 10\left(\mathrm{k} / \mathrm{k}_{\mathrm{p}}\right)>2.65$ and is chosen to merge with the value $S=0.68$ from Cox and Munk [8] over the capillary wave range. gravity waves than in the troughs. Zhang [38] observed the generation of parasitic capillary waves from the breaking of short gravity waves at wavelengths less than about $30 \mathrm{~cm}$.

The results of Wu are applicable to Cox and Munk's measurements in a fully developed open-sea environment, but they do not apply to wind-wave tank experiments, in which wind over a very short fetch was employed to generate waves. The lack of larger wavelength gravity waves in the tank experiments is likely to result in a higher density of gravity-capillary waves (more capillary waves per unit area), and produce larger MSS than over a fully developed sea at the same wind speed, as observed in Fig. 11.

It is clear from this discussion of Fig. 11 that an operational model for mean square slopes will need to rely heavily on the Cox and Munk data set. Fundamentally, the contribution of the long wavelength gravity waves to the MSS is very small and independent of wind speed. The MSS is so dominated by the short wavelength waves that, for practical purposes, it is impossible to ignore the Cox and Munk linear fit for any application which is based on the integrated effect over all wavelengths.

\section{COX AND MunK's EXPERIMENTS}

\section{A. Observations}

Between 25th August and 25th September, 1951, Charles Cox and Walter Munk conducted a series of experiments designed to determine the MSS of the ocean over a variety of wind conditions. All measurements were taken near Maui in the Hawaiian Islands. Their technique was based on aerial photographs of sun glitter taken from a B-17G (a modified Flying Fortress). The conditions at the sea surface were monitored from a $58-\mathrm{ft}$ schooner, The Reverie [8], which had two masts, each similar in height. Bendix Freiz Aerovane anemometers were installed on the fore masthead ( $41 \mathrm{ft}$ above sea level) and bowsprit ( $9 \mathrm{ft}$ above sea level) of the schooner. During each aerial photo, the ship would "heave to, with the wind abeam, and be steadied by sails" [8]. This means that the ship would be positioned side on to the wind, with the bow pointing slightly with the wind by between $20^{\circ}$ and $30^{\circ}$. The forward of the two masts would have its sail pushed fully to port, and the rear of the two masts would have its sail pushed fully to starboard. If this is done correctly, the ship would lean over slightly with the wind, the sails would be both full and the ship would "crab" toward an angle approximately halfway between the wind direction and the direction the ship is facing. If the skipper is skilled and the boat is set up well, then there should be little or no turbulence affecting the anemometers, although they would be measuring slightly under the actual wind speed. It is hard to see how this could be corrected since there would have been no way of accurately tracking the ship's position in real time. Although not mentioned in their paper, we must assume that no correction was made for this, or for the effect of ocean currents which would cause the ship to drift.

Other measurements made at the time of each aerial photo were, location, wind direction, sea surface temperature, air temperature, humidity, significant wave period, height, and direction. Notes were made on the state of the ocean (clean or oil 


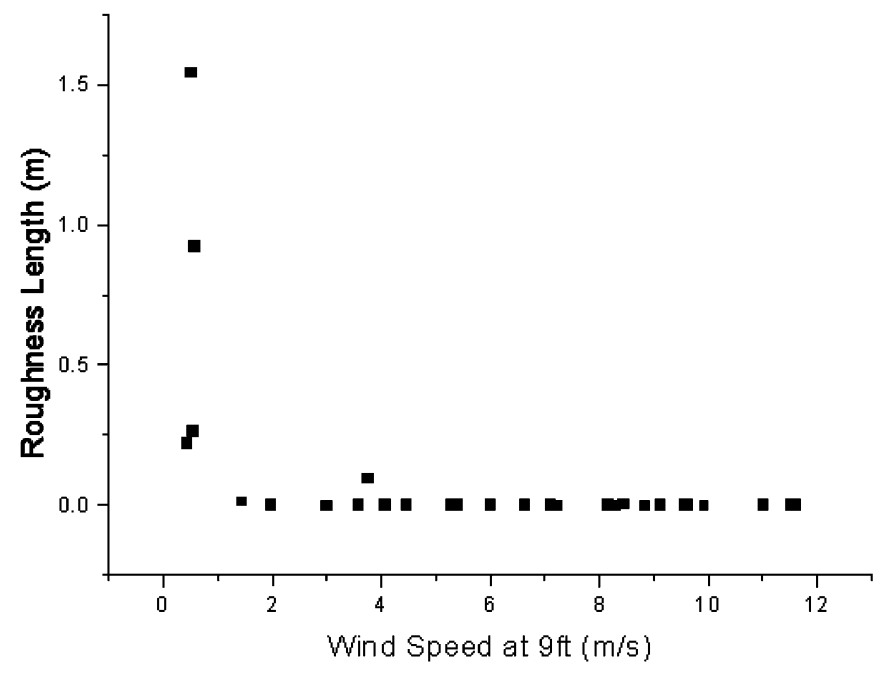

Fig. 12. Roughness length versus wind speed, from the data of Cox and Munk [8]. Two data points at low wind speeds are eliminated from the set on the grounds that they do not belong to the statistical ensemble.

slick), and times and dates were recorded. Later on, the sun's azimuth angles were calculated, based on time and location data.

\section{B. Cox and Munk Wind Speed Data}

Under neutral atmospheric conditions and constant eddy diffusivity, the wind profile near the water's surface can be expressed as

$$
\bar{U}(Z)=\frac{U_{*}}{k} \ln \left(\frac{z}{z_{0}}\right)
$$

where $\bar{U}(z)$ is the mean wind speed at a distance $(z)$ above the surface, $U_{*}$ is the frictional velocity, $k$ is the von Karman constant $(0.41), z$ is the height above the surface, and $z_{0}$ is the roughness length.

As explained above, Cox and Munk collected wind speed data from anemometers located at heights of 41 and $9 \mathrm{ft}$ above the sea surface. We are using the simple form of (5) to interpolate for wind speeds at an elevation of $10 \mathrm{~m}$, and with less justification we are using the stable atmosphere conditions to estimate $z_{0}$ values. Ten meters is an accepted reference height for meteorological measurements of wind speed, and the estimates of $z_{0}$ will allow us to identify the data points which are influenced by low wind speed and high friction effects. We are ignoring considerations of heat and water vapor fluxes in order to do this analysis and our only real justification is that the resulting straight-line fits to the data (refer to Figs. 13 and 14) are of good quality.

Fig. 12 presents the roughness length, $z_{o}$, plotted against the wind speed at an elevation of $9 \mathrm{ft}$. Clearly, the $z_{o}$ values for some low wind speeds do not belong to the same statistical group as the higher wind values for the purpose of establishing a characteristic roughness. High values of roughness length are typical for very low wind speed when the action of friction is more significant. For wind speeds greater than $0.6 \mathrm{~ms}^{-1}$, the mean and variance of the $23 z_{o}$ values are 0.0059 and 0.0199 , respectively (we use variance rather than standard deviation because the distribution is folded about zero and clearly not Gaussian).

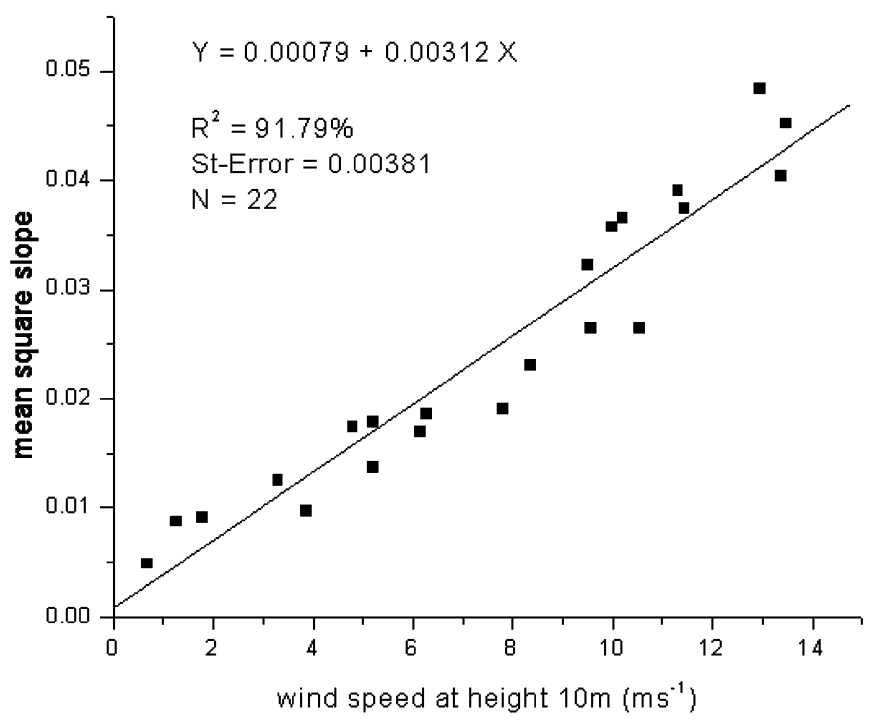

Fig. 13. Along-wind MSS versus wind speed, using modified data from Cox and Munk [8].

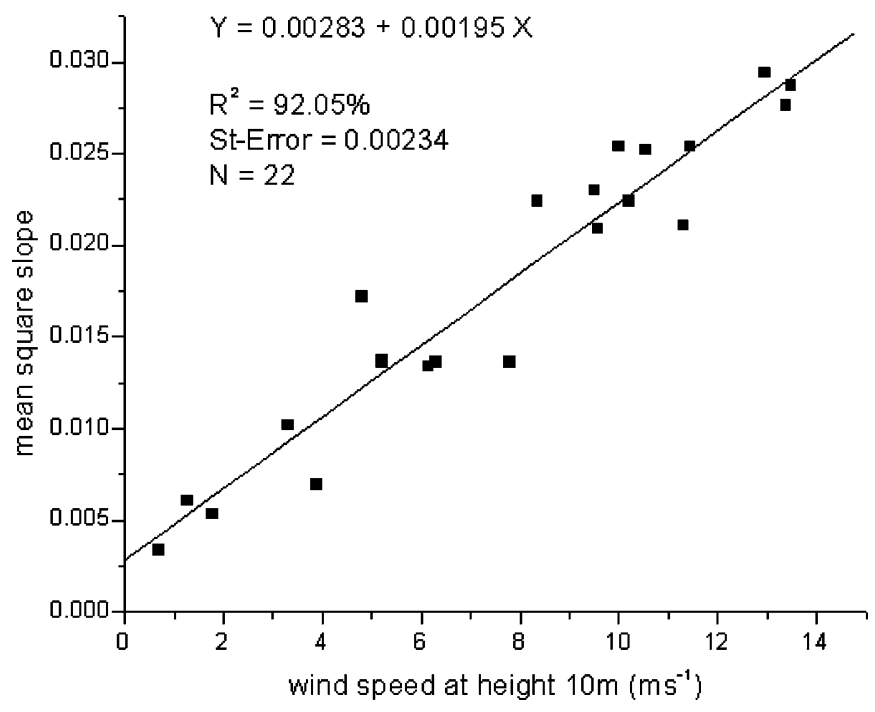

Fig. 14. Cross-wind MSS versus wind speed, using modified data from Cox and Munk [8].

We have excluded values which lie outside two variance intervals from the mean leaving $21 z_{o}$ values which have a mean of $0.0013 \mathrm{~m}$ and a variance of 0.0012 . Hence, for the purposes of this study, a value of $0.0013 \mathrm{~m}$ will be used for the roughness length $z_{o}$. Large and Pond [24] also reported that the roughness length of the ocean was relatively constant for wind speeds less than about $10 \mathrm{~ms}^{-1}$. The complication of increased friction at very low wind speeds is one that has yet to be addressed for microwave remote sensing. Wind speeds at a height of $10 \mathrm{~m}$ are calculated via this estimated roughness length for the wind measurements made by Cox and Munk and are presented in column 14 of Table II. Column 15 of this table is the wind fetch, calculated by plotting each data position on a chart and measuring the distance to land in the direction of the origin of the wind.

Since the short-wavelength waves are generated from local wind, it is also reasonable to assume that they are not significantly affected by fetch, unless the fetches are very small. Table II shows that the minimum fetch for these data is $10 \mathrm{~km}$, 
TABLE II

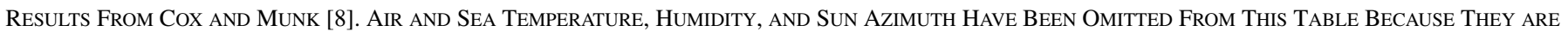
Not Relevant to This Paper. The Last Two Columns Have Been Derived From the Cox and Munk Results (SeE the Text for an Explanation). Wind Fetch has BeEn Presented Only for Clean SEAS

\begin{tabular}{|c|c|c|c|c|c|c|c|c|c|c|c|c|c|c|}
\hline \multirow{2}{*}{$\begin{array}{l}\text { Photo } \\
\text { Name }\end{array}$} & \multirow[b]{2}{*}{ Time } & \multicolumn{2}{|c|}{ Location } & \multicolumn{2}{|c|}{ Wind Speed } & \multirow{2}{*}{$\begin{array}{c}\text { Wind } \\
\text { Dir. } \\
\text { True N. }\end{array}$} & \multicolumn{3}{|c|}{ Significant Waves } & \multirow[t]{2}{*}{ Sea Surf. } & \multicolumn{2}{|c|}{ MSS } & \multirow{2}{*}{$\begin{array}{c}\text { Wind Speed } \\
10 \mathrm{~m} \\
(\mathrm{~m} / \mathrm{s})\end{array}$} & \multirow{2}{*}{$\begin{array}{l}\text { Wind } \\
\text { Fetch } \\
(\mathrm{km})\end{array}$} \\
\hline & & $\begin{array}{l}\text { Latitude } \\
\text { North }\end{array}$ & $\begin{array}{c}\text { Longitude } \\
\text { West }\end{array}$ & $\begin{array}{l}41 \mathrm{ft} \\
(\mathrm{m} / \mathrm{s})\end{array}$ & $\begin{array}{c}9 \mathrm{ft} \\
(\mathrm{m} / \mathrm{s})\end{array}$ & & $\begin{array}{l}\text { Height } \\
(\mathrm{m})\end{array}$ & $\begin{array}{l}\text { Period } \\
\text { (s) }\end{array}$ & $\begin{array}{c}\text { Dir. } \\
\text { True N. }\end{array}$ & & $\begin{array}{l}\text { across } \\
\text { wind }\end{array}$ & $\begin{array}{l}\text { with } \\
\text { wind }\end{array}$ & & \\
\hline 28 Aug. b & 1106 & $21^{\circ} 01.8^{\prime}$ & $156^{\circ} 45.8^{\prime}$ & 11.6 & 9.6 & $060^{\circ}$ & 3.5 & 4 & - & clean & .0211 & .0390 & 11.31 & inf. \\
\hline 28 Aug. p & 1336 & $20^{\circ} 59.0^{\prime}$ & $156^{\circ} 44.0^{\prime}$ & 13.3 & 11.0 & $050^{\circ}$ & 6 & 5 & $056^{\circ}$ & clean & .0294 & .0484 & 12.96 & inf. \\
\hline 28 Aug. u & 1403 & $20^{\circ} 58.2^{\prime}$ & $156^{\circ} 43.3^{\prime}$ & 13.8 & 11.6 & $050^{\circ}$ & 6 & 5 & $056^{\circ}$ & clean & .0287 & .0452 & 13.48 & 10 \\
\hline 28 Aug. v & 1403 & $20^{\circ} 58.2^{\prime}$ & $156^{\circ} 43.3^{\prime}$ & 13.7 & 11.5 & $050^{\circ}$ & 6 & 5 & $056^{\circ}$ & clean & .0276 & .0404 & 13.38 & 10 \\
\hline 3 Sept. j & 1157 & $20^{\circ} 39.5^{\prime}$ & $156^{\circ} 46.6^{\prime}$ & 0.72 & 0.45 & $050^{\circ}$ & 1.5 & 3 & $059^{\circ}$ & clean & .00337 & .00489 & 0.68 & 32 \\
\hline 3 Sept. q & 1330 & $20^{\circ} 39.5^{\prime}$ & $156^{\circ} 46.6^{\prime}$ & 8.58 & 7.11 & $120^{\circ}$ & 2 & 3 & $101^{\circ}$ & clean & .0224 & .0230 & 8.36 & 20 \\
\hline 3 Sept. $t$ & 1357 & $20^{\circ} 39.5^{\prime}$ & $156^{\circ} 46.6^{\prime}$ & 0.89 & 0.54 & $180^{\circ}$ & - & - & - & clean & .0152 & .0153 & 0.84 & inf. \\
\hline 4 Sept e & 1126 & $20^{\circ} 40.2^{\prime}$ & $156^{\circ} 40.3^{\prime}$ & 1.79 & 0.49 & $045^{\circ}$ & 1 & 2 & $120^{\circ}$ & oil & .00096 & .00126 & 1.60 & \\
\hline 4 Sept. k & 1158 & $20^{\circ} 39.0^{\prime}$ & $156^{\circ} 40.0^{\prime}$ & 3.93 & 3.58 & $100^{\circ}$ & 1 & 2 & $100^{\circ}$ & clean & .00694 & .00977 & 3.88 & 16 \\
\hline 4 Sept. $n$ & 1257 & $20^{\circ} 39.5^{\prime}$ & $156^{\circ} 36.9^{\prime}$ & 8.00 & 6.62 & $100^{\circ}$ & 2 & 3 & $106^{\circ}$ & clean & .0136 & .0191 & 7.80 & 20 \\
\hline 4 Sept. r & 1324 & $20^{\circ} 40.0^{\prime}$ & $156^{\circ} 39.3^{\prime}$ & 6.30 & 5.27 & $111^{\circ}$ & 4 & 3 & $106^{\circ}$ & clean & .0134 & .0170 & 6.15 & 16 \\
\hline 4 Sept. v & 1327 & $20^{\circ} 40.0^{\prime}$ & $156^{\circ} 39.3^{\prime}$ & 6.44 & 5.4 & $111^{\circ}$ & 4 & 3 & $106^{\circ}$ & clean & .0136 & .0186 & 6.29 & 16 \\
\hline 4 Sept. y & 1353 & $20^{\circ} 39.5^{\prime}$ & $156^{\circ} 36.9^{\prime}$ & 4.92 & 4.07 & $110^{\circ}$ & 4 & 3 & $100^{\circ}$ & clean & .0172 & .0174 & 4.80 & 20 \\
\hline 5 Sept. b & 1058 & $20^{\circ} 40.5^{\prime}$ & $156^{\circ} 35.7^{\prime}$ & 1.83 & 1.43 & $280^{\circ}$ & 3 & 4 & $160^{\circ}$ & clean & .00534 & .00906 & 1.77 & 30 \\
\hline 5 Sept. $g$ & 1124 & $20^{\circ} 40.1^{\prime}$ & $156^{\circ} 35.4^{\prime}$ & 1.39 & 0.58 & $280^{\circ}$ & 3 & 4 & $104^{\circ}$ & clean & .00609 & .00875 & 1.27 & 30 \\
\hline 5 Sept. j & 1354 & $20^{\circ} 46.8^{\prime}$ & $156^{\circ} 40.3^{\prime}$ & 3.35 & 2.99 & $225^{\circ}$ & 5 & 4 & $140^{\circ}$ & clean & .0102 & .0125 & 3.30 & inf. \\
\hline 6 Sept. c & 1048 & $20^{\circ} 58.5^{\prime}$ & $156^{\circ} 45.3^{\prime}$ & 10.8 & 9.12 & $045^{\circ}$ & 4 & 4 & $045^{\circ}$ & clean oil & $\begin{array}{l}.0252 \\
0111\end{array}$ & $\begin{array}{l}.0265 \\
0108\end{array}$ & 10.55 & inf. \\
\hline 6 Sept. k & 1124 & $20^{\circ} 58.0^{\prime}$ & $156^{\circ} 44.5^{\prime}$ & 10.2 & 8.85 & $045^{\circ}$ & 4 & 4 & $045^{\circ}$ & clean & .0254 & .0357 & 10.00 & inf. \\
\hline 6 Sept. q & 1237 & $20^{\circ} 57.5^{\prime}$ & $156^{\circ} 44.0^{\prime}$ & 11.7 & 9.92 & $045^{\circ}$ & 5 & 4 & $045^{\circ}$ & clean & .0254 & .0374 & 11.44 & inf. \\
\hline 10 Sept. k & 1328 & $20^{\circ} 40.0^{\prime}$ & $156^{\circ} 38.3^{\prime}$ & 8.45 & 7.24 & $130^{\circ}$ & 3 & 3 & $090^{\circ}$ & oil & .0102 & 0117 & 8.27 & \\
\hline 10 Sept. m & 1333 & $20^{\circ} 40.0^{\prime}$ & $156^{\circ} 38.3^{\prime}$ & 7.15 & 6.00 & $130^{\circ}$ & 3 & 3 & $090^{\circ}$ & oil & .00860 & .0100 & 6.98 & \\
\hline 10 Sept. $\mathrm{r}$ & 1347 & $20^{\circ} 39.7^{\prime}$ & $156^{\circ} 39.3^{\prime}$ & 5.32 & 4.47 & $120^{\circ}$ & 3 & 3 & $090^{\circ}$ & clean oil & $\begin{array}{l}.0137 \\
00967\end{array}$ & $\begin{array}{l}.0179 \\
00985\end{array}$ & 5.20 & 30 \\
\hline 11 Sept. e & 1317 & $20^{\circ} 45.5^{\prime}$ & $156^{\circ} 41.8^{\prime}$ & 5.45 & 3.75 & $210^{\circ}$ & 2 & 3 & $120^{\circ}$ & clean & .0136 & .0137 & 5.20 & inf. \\
\hline 11 Sept. f & 1317 & $20^{\circ} 45.5^{\prime}$ & $156^{\circ} 41.8^{\prime}$ & 5.45 & 3.75 & $210^{\circ}$ & 2 & 3 & $120^{\circ}$ & oil & .0107 & .0109 & - & \\
\hline 13 Sept. e & 1308 & $20^{\circ} 17.6^{\prime}$ & $156^{\circ} 02.4^{\prime}$ & 2.41 & 1.97 & $090^{\circ}$ & 4 & 5 & $075^{\circ}$ & oil & .00391 & .00467 & 2.35 & \\
\hline 13 Sept. f & 1308 & $20^{\circ} 17.6^{\prime}$ & $156^{\circ} 02.4^{\prime}$ & 2.41 & 1.97 & $090^{\circ}$ & 4 & 5 & $075^{\circ}$ & oil & .00724 & .00959 & - & \\
\hline 17 Sept. e & 1136 & $20^{\circ} 29.9^{\prime}$ & $156^{\circ} 24.8^{\prime}$ & 9.79 & 8.31 & $086^{\circ}$ & 4 & 3 & $080^{\circ}$ & clean oil & $\begin{array}{l}.0209 \\
.0106\end{array}$ & $\begin{array}{l}.0264 \\
.0126\end{array}$ & $\begin{array}{c}9.57 \\
-\end{array}$ & inf. \\
\hline 17 Sept. c, h, k, n, q & 11111205 & $20^{\circ} 28^{\prime}$ & $156^{\circ} 24^{\prime}$ & 9.74 & 8.18 & $088^{\circ}$ & 4 & 3 & $080^{\circ}$ & clean & .0230 & .0322 & 9.51 & inf. \\
\hline 17 Sept. A & 1424 & $20^{\circ} 17.6^{\prime}$ & $156^{\circ} 14.8^{\prime}$ & 10.5 & 8.45 & $068^{\circ}$ & 5 & 3 & $080^{\circ}$ & clean & .0224 & .0365 & 10.2 & \\
\hline
\end{tabular}

so this assumption should hold. Since we have found that the MSSs of long-wavelength gravity waves are also insensitive to fetch, the open sea wave slope measurements made by Cox and Munk can be assumed to be free of any fetch limitations.

There is one point missing from this wind-wave cross check, and that is the set of measurements labeled " 3 Sept. t" in Table II. This point was omitted because it has no associated wave data. From Table II, it can be seen that this set of data has a corresponding $10-\mathrm{m}$ wind speed of $0.84 \mathrm{~ms}^{-1}$ at a direction of $180^{\circ}$. The previous set of data to this was taken only $27 \mathrm{~min}$ earlier and in exactly the same location. This earlier set of measurements has a corresponding $10-\mathrm{m}$ wind speed of $8.36 \mathrm{~ms}^{-1}$ with a direction of $120^{\circ}$. Clearly the data associated with " 3 Sept. t" represents a confused sea with several cross-components of waves. As a result, we have chosen to omit this point from the analysis. In this analysis, Cox and Munk's remaining 21 data points of MSS versus wind speed (Figs. 13 and 14) for clean seas form a self-consistent set. Hwang [17] used a different self-consistency argument to adjust some of the low wind speed data points in Cox and Munk's table of data.

Figs. 13 and 14 are the plots of Cox and Munk's remaining 21 values for the along-wind and cross-wind MSS data, respectively. The figures also show the results of a least squares straight line fit of each of the data sets. The $y$-intercepts at zero wind speed presumably represent MSS slopes from swell propagating into the study region. If we assume that the $y$-intercepts represent a background swell MSS and that this is indicative of the effect of swell throughout the study, then this will represent an offset in MSS rather than a change in slope. Therefore, in for- mulating a wind-driven model, we consider only the slopes of these least square lines

$$
\begin{aligned}
\text { cross-wind : } \sigma_{c}^{2} & =0.00195 U_{10} \\
\text { along-wind : } \sigma_{w}^{2} & =0.00312 U_{10}
\end{aligned}
$$

where $\sigma^{2}$ represents the MSS. These wave slopes are an order of magnitude larger than those calculated above for the JONSWAP spectrum. This confirms that MSS are dominated by short gravity waves and capillaries.

\section{Directional Spreading of Short Waves}

The data for directional spreading of the short gravity-capillary waves are quite varied. Efouhaily et al., [11] presented a summary of five options and presented them as graphs of delta ratio versus wavenumber. Two of the models had a constant delta ratio over the relevant wavenumber band with values at $\Delta=0$ [31] and $\Delta=0.17$ [1]. The other three had a maximum of $\Delta \approx 0.48$ at the gravity-capillary wave peak and the model adopted by Elfouhaily et al. has $\Delta_{m}$ at the gravity-capillary wave peak almost linearly dependent on wind speed.

The relationship between $\Delta$ and the orthogonal MSS observations is

$$
\Delta(k)=\frac{\sigma_{w}^{2}-\sigma_{c}^{2}}{\sigma_{w}^{2}+\sigma_{c}^{2}}
$$

and on substitution of the values from the Cox and Munk data set $\Delta=0.231$, which is independent of wind speed 
and wavenumber, but represents a weighted average over all wavenumbers.

As in previous literature, we have only one parameter to specify the directional spreading, but for the short-wavelength part of the spectrum (wavenumbers greater than the transition $k_{t}$ ), we will assume a unimodal shape. Anyone wanting to use the spectral model for the interpretation of remote sensing data may need to assume a form for the wave energy as a function of angle to the wind direction. Since the directional spectrum for gravity-capillary waves is unimodal, we could adopt any of several which are in common use. The delta ratio parameter adopted by Elfouhaily et al., [11] is useful as the single parameter, but their spreading shape function is

$$
G(\theta)=\frac{[1+\Delta \cos (2 \theta)]}{(2 \pi)}
$$

which is folded about $\theta= \pm \pi / 2$. This is directly applicable in analysis of data when the scattering cross section depends on wavenumber spectra, with no Doppler shifts to resolve directional ambiguity. A more fundamental specification of directional spreading for a unimodal shape is the $S$ parameter of Mitsuyasu et al. [31] and Longuet-Higgins et al. [28], and the $\beta$ parameter of Donelan et al. [10]. There is an analytical conversion between the $S$ parameter and the delta ratio. We prefer to avoid the complication of waves travelling directly up-wind included in the Donelan et al. model, because this is thought to be predominantly due to an interaction with longer waves. If this is happening, then it could be explicitly included in any analysis in a way which is specific to the situation. For the gravity-capillary wave band, we retain the shape function of Mitsuyasu et al. [31] and Longuet-Higgins et al. [28]

$$
G(\theta, k)=A(k) \cos ^{2 S}\left(\frac{\theta}{2}\right),
$$

which can be folded if the application is insensitive to against-wind and along-wind differentiation. This is consistent because the bimodal shape for the longer gravity waves is also unfolded - it is based on Ewans' [12] time series data.

The equivalence between the spreading parameters $S$ and $\Delta$ is analytical, given by

$$
\Delta(k)=\tanh \left(\frac{\ell n 2}{2} S\right) .
$$

In this section on short waves, we have used Cox and Munk's MSS data to determine the spreading parameter. In many cases, the required application is for the spectral energy density for water elevation $R(k)$, where the variance is

$$
\sigma_{1}^{2}=\int R(k) d k
$$

and the variance of the distribution of wave slopes is

$$
\sigma_{2}^{2}=\int k^{2} R(k) d k \text {. }
$$

This means that for a limited bandwidth, like the gravity-capillary waves, the directionality applies to both the elevation and the slope distributions.

\section{NEW SyNTHESISEd MODEL FOR THE SPREADING OF GRAVITY AND CAPILLARY WAVES}

In this paper, we have not considered spectral amplitude and we will adopt the model of Elfouhaily et al. [11] for spectral amplitudes. In doing so we are adopting their transition from the long-wave spectral form to the short-wave form according to the condition given in (3) and illustrated by the circles plotted in Fig. 8. The wavenumber for the transition lies in the range $89>k_{T} / k_{p}>178$ and is almost independent of wind speed as shown in Fig. 8. The main hard data we have for this transition comes from the work of Jahne and Riemer [20] shown in Table I and the data plotted in Fig. 10 where the transition zone is $148<k / k_{p}<447$. While the data are in broad agreement with the estimate of Elfouhaily et al. [11], we do not have much precision, and our model will simply require $S=0$ (and $\Delta=0$ ) in the transition zone. The specification of the spreading is therefore in three sections.

For $1.4<k / k_{p}<89$ the form is bimodal with peak separation given by

$$
\Delta \theta=\exp \left[4.836-7.408\left(\frac{k}{k_{p}}\right)^{-\frac{3}{2}}\right]
$$

with each peak having a Gaussian shape with

$$
\sigma=32.13-\frac{3.92 k_{p}}{k} \text {. }
$$

For $89<k / k_{p}<148$, the $S$-value goes linearly (with $\log _{10}\left(\mathrm{k} / \mathrm{k}_{\mathrm{p}}\right)$ to zero at $\log _{10}\left(k / k_{p}\right)=2.17$. The $S$-value remains at zero until $\log _{10}\left(k / k_{p}\right)=2.65$.

For $467<k / k_{p}$ the spectrum is unimodal and becomes dominated by capillary waves. The data from Jahne and Riemer shown in Fig. 10 indicate that the spreading parameter increases from zero at the end of the transition region in a manner consistent with the $\mathrm{k} / \mathrm{k}_{\mathrm{p}}$ normalization. Recent approaches to modeling the generation of capillary waves in the ocean have shown that within a specific wavenumber band, breaking gravity waves can generate capillaries. The generation of parasitic capillary waves from the breaking of steep gravity waves was introduced by Longuet-Higgins, [27] and developed by Belcher and Vassilicos, [5] to investigate energy balance in the short gravity wave-capillary wave spectra. The idea is that gravity waves with wavelength less than about $0.3 \mathrm{~m}$ have phase velocities which map across to the capillary wave band. When one of these gravity waves breaks, the energy can transfer to the capillary wave with the phase velocity which matches the momentary surge velocity of the breaker. Kudryavtsev et al. [23] have developed a spectral model for capillary waves based on this energy source and ignoring all others including wave-wave interactions. The spectral broadening of the Kudryavtsev et al. model in the capillary range is weakly dependent on wind speed, and in this respect differs from the Elfouhaily et al. model. The Elfouhaily et al. model includes a spreading parameter which, in the capillary range, has a strong approximately linear dependence on wind speed. This is not strongly based on data, and the authors acknowledge it to be a point for further development. One complication with a strongly wind dependent $S$-value is that the ratio $\sigma_{c}^{2} / \sigma_{w}^{2}$ from 
Cox and Munk's [8] data is independent of wind speed. While it is possible for the weighted integral to be independent of wind speed when the wavenumber spectrum itself shows wind speed dependence, it would require a complexity which we cannot support with data or theory. The calculations of Kudryavtsev $e t$ al. show (their Fig. 6) that the weakly wind dependent angular width has a mean value of $\sigma_{c}^{2} / \sigma_{w}^{2}=0.60$, compared with the value 0.625 from the data of Cox and Munk, [8].

On the basis of this, we will adopt a constant value of $\sigma_{c}^{2} / \sigma_{w}^{2}=0.625$ for the capillary range. For $467<k / k_{p}$, we suggest an empirical form based on Fig. 10 for the emergence from the transition band, where the $k / k_{p}$ normalization is important, and the asymptotic $S$-value of 0.68 for the capillaries where the $k / k_{p}$ normalization is not relevant. It has the form

$$
S=0.68\left(1-\exp \left(-\frac{\log _{10}\left(\frac{k}{k_{p}}\right)-2.65}{0.1}\right)\right) .
$$

This model shape is shown in Fig. 10 as the dashed line.

\section{CONCLUSION}

We have reconsidered the shape of the wind wave spectrum for all wavenumbers greater than that at the gravity wave peak. The directional spreading was perhaps the least accurate of all the parameters in the unified spectrum suggested by Elfouhaily et al. [11], and this reflects the recent changes in the descriptions of the fundamental processes which shape the wind wave spectrum. We have adopted the theoretical results of Kudryavtsev $e t$ al. [23] for the spectral spreading in the capillary range because they are more consistent with the data of Cox and Munk [8] for the weighted average of the spreading.

In our model, we have included bimodality of the directional spectrum for gravity wave wavenumbers above the peak, and the transition back to unimodality in the gravity-capillary wave part of the spectrum. In the transition range, the spectrum is effectively omnidirectional. This transition range is not the same as that discussed by Kudryavtsev et al. [23] because it occurs at a longer wavelength at about $0.3-1 \mathrm{~m}$. We suggest that this transition is controlled by the wind wave spectrum because the normalization of the wavenumber to the gravity wave peak value. The best theoretical and observational evidence is for a spreading parameter which is independent of wind speed and wavenumber over the capillary wave band.

The resulting description of the directional spreading parameter is simple and elegant, with no dependence on wind speed when the wavenumbers are normalized to $k_{p}$.

\section{REFERENCES}

[1] J. R. Apel, "An improved model of the ocean surface wave vector spectrum and its effects on radar backscatter," J. Geophys. Res., vol. 99, pp. 16 269-16291, 1994.

[2] M. L. Banner, "Equilibrium spectra of wind waves," J. Phys. Oceanogr., vol. 20, pp. 966-984, 1990.

[3] M. L. Banner, I. S. F. Jones, and J. C. Trinder, "Wavenumber spectra of short gravity waves," J. Fluid Mech., vol. 198, pp. 321-344, 1989.

[4] M. L. Banner and I. R. Young, "Modeling spectral dissipation in the evolution of wind waves. Part I: Assessment of existing model performance," J. Phys. Oceanogr., vol. 24, pp. 1550-1571, 1994.
[5] S. E. Belcher and J. C. Vassilicos, "Breaking waves and the equilibrium range of wind-wave spectra," J. Fluid Mech., vol. 342, pp. 377-401, 1997.

[6] R. A. Brown, "On a satellite scatterometer as an anemometer," J. Geophys. Res., vol. 88, pp. 1663-1673, 1983.

[7] C. S. Cox, "Measurements of slopes of high-frequency waves," J. Mar. Res., vol. 16, pp. 199-225, 1958.

[8] C. Cox and W. H. Munk, "Statistics of the sea surface derived from sun glitter," J. Mar. Res., vol. 13, pp. 198-227, 1954.

[9] G. D. Crapper, Introduction to Water Waves. New York: Halsted, 1984.

[10] M. A. Donelan, J. Hamilton, and W. H. Hui, "Directional spectra of wind-generated waves," Philos. Trans. R. Soc. London, vol. A315, pp. 509-562, 1985.

[11] T. Elfouhaily, B. Chapron, K. Katsaros, and D. Vademark, "A unified directional spectrum for long and short wind-driven waves," J. Geophys. Res., vol. 102, pp. 15 781-15 796, 1997.

[12] K. C. Ewans, "Observations of the directional spectrum of fetch-limited waves," J. Phys. Oceanogr., vol. 28, pp. 495-512, 1998.

[13] S. P. Haimbach, "Development of slope spectra of the wind-disturbed water surface," Ph.D. dissertation, Univ. Delaware, Newark, 1985.

[14] K. Hasselmann, "On the spectral dissipation of ocean waves due to whitecapping," Boundary Layer Meteor., vol. 6, pp. 107-127, 1974.

[15] M. L. Heron, "Directional spreading of short wavelength fetch-limited wind wave," J. Phys. Oceanogr., vol. 17, pp. 281-285, 1987.

[16] M. L. Heron and G. Bold, James Cook Univ., Townsville, Queensland, Australia, Tech. Rep., 1999.

[17] P. Hwang, "A study of the wavenumber spectra of short water waves in the ocean. Part II: spectral model and mean square slope," J. Atmos. Ocean. Tech., vol. 14, pp. 1174-1186, 1997.

[18] P. A. Hwang, D. W. Wang, E. J. Walsh, W. B. Krabill, and R. N. Swift, "Airborne measurements of the wavenumber spectra of ocean surface waves. Part II: Directional distribution,” J. Phys. Oceanogr., vol. 30, pp. 2768-2787, 2000.

[19] P. A. Hwang and D. W. Wang, "Directional distributions and mean square slopes in the equilibrium and saturation ranges of the wave spectrum," J. Phys. Oceanogr., vol. 31, pp. 1346-1360, 2001.

[20] B. Jahne and K. S. Riemer, "Two-dimensional wave number spectra of small-scale water surface waves," J. Geophys. Res., vol. 95 C7, pp. 11531-11546, 1990.

[21] W. L. Jones, L. C. Schroeder, and J. L. Mitchell, "Aircraft measurements of the microwave scattering signature of the ocean," IEEE J. Oceanic Eng., vol. 2, no. 1, pp. 52-67, Jan. 1977.

[22] W. C. Keller and W. J. Plant, "Cross sections and modulation transfer functions at $\mathrm{L}$ and $\mathrm{Ku}$ bands measured during the tower ocean wave and radar dependence experiment," J. Geophys. Res., vol. 95 C9, pp. 16277-16289, 1990.

[23] V. N. Kudryavtsev, V. K. Makin, and B. Chapron, "Coupled sea surfaceatmosphere model 2. Spectrum of short wind waves," J. Geophys. Res., vol. 104 , pp. 7,625-7,639, 1999.

[24] W. G. Large and S. Pond, "Sensible and latent heat flux measurements over the ocean," J. Phys. Ocean., vol. 12, pp. 464-482, 1982.

[25] P. H. Leblond and L. A. Mysak, Waves in the Ocean, ser. Elsevier Oceanography Series. Amsterdam, The Netherlands: Elsevier, 1980.

[26] S. R. Long and N. E. Huang, "On the variation and growth of wave-slope spectra in the capillary-gravity range with increasing wind," J. Fluid. Mech., vol. 77, pp. 209-228, 1976.

[27] M. S. Longuet-Higgins, "The generation of capillary waves by steep gravity waves," J. Fluid Mech., vol. 16, pp. 138-159, 1963.

[28] M. S. Longuet-Higgins, D. E. Cartwright, and N. D. Smith, "Observations of the directional spectrum of sea waves using the motions of a flotation buoy," in Ocean Wave Spectra. Englewood Cliffs, NJ: Prentice-Hall, 1963, pp. 111-136.

[29] S. R. Massel, "Ocean surface waves: Their physics and prediction," in Advanced Series on Ocean Engineering-Volume II, Singapore: World Scientific, 1996.

[30] H. Mitsuyasu, "Measurements of the high frequency spectrum of the ocean surface waves," J. Phys. Ocean., vol. 7, pp. 882-891, 1977.

[31] H. Mitsuyasu, F. Tasai, T. Suhara, S. Misuno, M. Ohkuso, T. Honda, and K. Rindiishi, "Observations of the directional spectrum of ocean waves using a cloverleaf buoy," J. Phys. Oceanogr., vol. 5, pp. 750-760, 1975.

[32] A. H. Schooley, "A simple optical method for measuring the statistical distribution of water surface slopes," J. Opt. Soc. Amer., vol. 44, pp. 37-40, 1954.

[33] D. W. Wang and P. A. Hwang, "Evolution of the bimodal directional distribution of ocean waves," J. Phys. Oceanogr., vol. 31, pp. 1200-1221, 2001. 
[34] J. W. Wright and W. C. Keller, "Doppler spectra in microwave scattering from wind waves," Phys. Fluids, vol. 14, pp. 466-474, 1971

[35] J. Wu, "Effects of long waves on wind boundary layer and on ripple slope statistics," J. Geophys. Res., vol. 82, pp. 1359-1362, 1977.

[36] J. Wu, "Distribution and steepness of ripples on carrier waves," J. Phys. Ocean., vol. 9, pp. 1014-1021, 1979.

[37] I. R. Young, L. A. Verhagen, and M. L. Banner, "A note on the bimodal directional spreading of fetch-limited wind waves," J. Geophys. Res., vol. $100 \mathrm{C} 1$, pp. 773-778, 1995.

[38] X. Zhang, "Capillary-gravity and capillary waves generated in a wind wave tank: observations and theories," J. Fluid Mech., vol. 289, pp. $51-82,1995$.

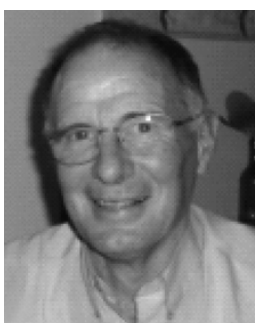

Malcolm L. Heron (SM'93) received the B.Sc. and M.Sc. degrees in physics from the University of Auckland, Auckland, New Zealand, in 1965 and 1967, respectively, and the Ph.D. degree in radio science from the University of Auckland in 1971.

$\mathrm{He}$ is a Professor of physics at James Cook University, Townsville, Queensland, Australia. His research interests include the physics of remote sensing, and he has been involved in the development of HF and VHF ocean surface radar for many years. More recently, he has worked on radiometry, and in particular, the sensing of sea surface salinity by microwave radiometers.

Prof. Heron is an Associate Editor of the IEEE JouRnAL OF OCEANIC ENGINEERING.

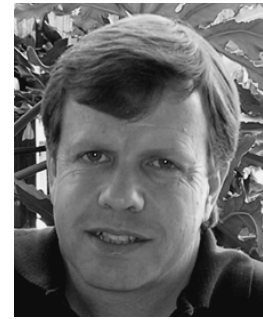

William J. Skirving received the B.Sc. degree in mathematics and geography and the M.Sc. degree in hydrology from the University of Tasmania, Hobart, Australia, in 1984 and 1989, respectively, and the Ph.D. degree in satellite oceanography from the School of Mathematical and Physical Sciences, James Cook University, Townsville, Queensland, Australia, in 2001.

$\mathrm{He}$ is the Director of the Satellite Division, QSEC, Townsville. His research interests include the physics of remote sensing, and he has recently concentrated on the development of techniques for monitoring and predicting coral bleaching. More recently, he has worked for three years as a Visiting Scientist at NOAA/NESDIS, Silver Spring, MD, where he is one of the Senior Scientists on the Coral Reef Watch project.

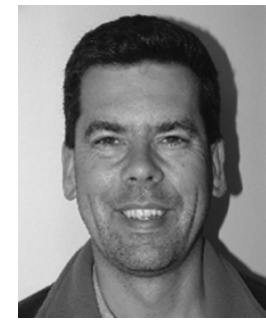

Kelvin J. Michael received the Ph.D. degree in climatology and oceanography from the University of Tasmania, Hobart, Australia, in 1989.

From 1987 to 1990, he was a Research Scientist with the Surveillance Research Laboratory, Defence Science and Technology Organization, Adelaide, Australia. In 1991, he joined the Institute of Antarctic and Southern Ocean Studies, University of Tasmania, Hobart, where he conducts research into remote sensing of the ocean and sea ice, and teaches physics, remote sensing, and Antarctic studies. 